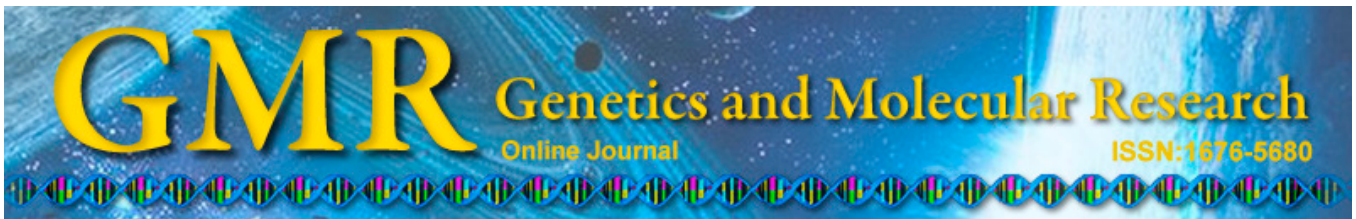

\title{
Genetic divergence among sweet corn lines estimated by microsatellite markers
}

\author{
A.D. Lopes ${ }^{1}$, C.A. Scapim ${ }^{2}$, C.A. Mangolin $^{3}$ and M.F.P.S. Machado ${ }^{3}$ \\ ${ }^{1}$ Programa de Pós-Graduação em Genética e Melhoramento, \\ Universidade Estadual de Maringá, Maringá, PR, Brasil \\ ${ }^{2}$ Departamento de Agronomia, Universidade Estadual de Maringá, \\ Maringá, PR, Brasil \\ ${ }^{3}$ Departamento de Biotecnologia, Genética e Biologia Celular, \\ Universidade de Maringá, Maringá, PR, Brasil \\ Corresponding author: A.D. Lopes \\ E-mail: anadanielalopes@yahoo.com.br
}

Genet. Mol. Res. 13 (4): 10415-10426 (2014)

Received November 14, 2013

Accepted July 29, 2014

Published December 12, 2014

DOI http://dx.doi.org/10.4238/2014.December. 12.3

\begin{abstract}
The purpose of this study was to analyze the genetic diversity of 15 sugary-1 sweet corn lines by microsatellite markers. One hundred pairs of simple sequence repeat primers that were mapped for field corn were tested. Of these primers, $15 \%$ were polymorphic, and all were selected for the evaluation. These primers identified a total of 39 alleles among the 15 loci that were evaluated. The number of alleles per locus in the genotypes ranged from 2 to 4 , with an average of 2.60 alleles per locus; the highest number of alleles was observed at the loci Bnlg1083, Umc1241, and Umc1590. The occurrence of null alleles at locus Umc1363 was evident only in line DN44. The proportion of polymorphic loci was the highest in lines DN17.1 and DN6 (73.33\%), whereas lines DN47, DN23, and DN28 were more monomorphic than other lines. The loci Bnlg1083 and Umc1506 were polymorphic in 8 and 7 lines, respectively, indicating that these loci might be effective and promising for the identification of polymorphism in other sweet corn lines. The genetic diversity calculated by Rogers' genetic
\end{abstract}


distances indicated the lowest genetic similarity between lines DN9 and DN28 (0.7603) and the highest similarity between lines DN19 and DN6 (0.3724). The dendrogram obtained by the unweighted pairgroup method based on arithmetic averages indicated the formation of 4 major groups, showing the crossing of the genotypes DN19 and DN6 with DN8 as a possible alternative for the expression of heterozygosis.

Key words: Zea mays L.; Sweet corn; Genetic divergence; Simple sequence repeat markers

\section{INTRODUCTION}

Among the species that are native to the Americas, corn is certainly the most important worldwide in economic and social terms with respect to cultivation area and yield. In Brazil, corn is grown in every state of the federation and on most farms. Because of its great adaptability to different environments, the crop is grown in approximately 70 countries, on an area of over 100 million hectares (Laborda, 2003). In Brazil, corn is grown on around 36 hectares, and almost $100 \%$ is destined for industrial processing (Barbieri et al., 2005).

As one of the largest producers of corn in the world, Brazil clearly has the potential to produce specialty corns, including sweet corn (Bordallo et al., 2005). This species has intrinsic characteristics that differentiate it from field corn. The difference lies in the seed, which slowly dries after maturation and, once dry, becomes glassy and wrinkled-glassy because of the crystallization of a high concentration of sugar and wrinkled because of the small proportion of starch in the endosperm (Storck and Lovato, 1991).

With regard to the improvement of sweet corn, until 1978, a single variety adapted to Brazilian conditions, Doce de Cuba, was produced commercially; it was productive, but its quality was unsatisfactory because of the coarse texture of the pericarp (Garcia et al., 1978). Silva et al. (1978) mentioned a sweet corn type, Nutrimaiz, which contains the mutant gene sugary associated with the opaque-2 gene in an attempt to improve the protein quality of sweet corn for consumption.

The Centro Nacional de Pesquisa de Hortaliças, EMBRAPA, together with the Centro Nacional de Pesquisa de Milho e Sorgo, EMBRAPA, developed and released 3 sweet corn cultivars in 1984: Superdoce, Doce-de-ouro, and Doce-cristal. Later, 2 new hybrids were released, Lili and Docemel (Reifschneider et al., 1984). A basic seed production program was established for these lines to meet the demand of seed companies, agribusinesses, and other users. At this point, it was observed that the seed quality was not always satisfactory; in some cases, a low germination rate and incidence of seed microorganisms caused major problems (Nascimento et al., 1994).

Padilha et al. (2003) suggested that the incorporation of microsatellite marker technology in the breeding program is an accurate and efficient strategy that could ensure high standards of genetic purity in the elite lines and seeds of hybrid corn. Aside from the phenotypic characteristics, this technique provides information about genetic variability that is derived directly from the DNA, representing a major advantage in the selection of plants to be used as a source of genetic seeds. In this context, microsatellite markers are the most appropriate method to monitor genetic purity because they are multi-allelic, co-dominant, and contain a high amount of genetic information per locus; their co-dominance enables the identification of 
the different parental contributions to the progenies. Another advantage of microsatellites is that they only require a small amount of DNA that can be extracted from any biological material, seed, or seedling at any stage of development, allowing an early and efficient evaluation of the seed lots (Padilha et al., 2003).

The standard sweet corn is homozygous for the recessive gene sugary-1 (sul) (Wann et al., 1971) and is characterized by carrying at least 1 of the 8 mutant genes that affect carbohydrate biosynthesis in the endosperm, including shrunken-2 on chromosome 3 , brittle on chromosome 5, and sugary enhancer, sugary (su), and brittle-2 on chromosome 4. In addition, dull is on chromosome 10, waxy is on chromosome 9, and amylose extender is on chromosome 5. These genes can act singly or in double or triple combinations. However, some undesirable characteristics are associated with these genes (e.g., low yield and low resistance to pests and diseases) because of the higher sugar content than that of normal corn (Oliveira Júnior et al., 2006). The $s u$ allele does not determine an exceptional sugar content; instead, it influences high levels of phyto-glycogen or water-soluble polysaccharides and a low starch content.

Because the genetic characterization of corn is recent, information about the diversity of the sul gene is still incomplete (Tracy et al., 2006). There are few published articles that describe the genetic structure and diversity among sweet corn varieties (Liu et al., 2003; Nigussie and Saleh, 2007), particularly of the sul germplasm from southern Brazil (Bered et al., 2005). Therefore, because of the great interest in the production of sweet corn in Brazil and the lack of information on the genetic divergence between populations, the purpose of this study was to investigate the genetic diversity of $15 \mathrm{sul}$ sweet corn lines using microsatellite markers.

\section{MATERIAL AND METHODS}

A total of 15 lines (S5) of sweet corn were selected to represent part of the diversity available in the Universidade Estadual de Maringá (UEM), PR, Brazil, sul germplasm collection. Selections were made from the BR401-sugary-1 population provided by the Centro Nacional de Pesquisa de Hortaliças, Brasília, and the Centro Nacional de Pesquisa de Milho e Sorgo, Sete Lagoas, MG, Brazil.

Approximately 20 seeds of each line were sown in small baskets containing soil and maintained at the ideal temperature for development. Genomic DNA was isolated from young leaves of 10 plants of each line according to the method described by Hoisington et al. (1994).

For the amplification reactions with simple sequence repeat (SSR) primers, 5 of the 10 plants from which DNA was extracted were selected. The 100 SSR primers that were previously mapped in corn were obtained from the website http://www.maizegdb.org. After testing the 100 primers, a total of 15 primers (Table 1) were selected for further analysis.

Polymerase chain reaction (PCR) was performed using a thermal cycler (Techne TC512 - USA). To amplify the microsatellite loci, a touchdown program (Don et al., 1991) was used initially except in the case of primer Umc1241, for which the annealing temperature was changed to $50^{\circ} \mathrm{C}$. The reactions were prepared with $25 \mathrm{ng}$ genomic DNA, $2.0 \mu \mathrm{L} 10 \mathrm{X}$ reaction buffer (Invitrogen), $2.0 \mathrm{mM} \mathrm{MgCl}, 0.1 \mathrm{mM}$ of each dNTP, 1 unit Taq polymerase (Invitrogen), and $0.2 \mathrm{~mL}$ of each primer ( $\mathrm{F}^{2}$ and $\mathrm{R}$ ) in a final volume of $20 \mu \mathrm{L}$.

The amplified samples were fractionated on a $4 \%$ agarose gel $(50 \%$ common agarose and 50\% MS-8 agarose), diluted and buffered in 0.5X TBE (44.5 mM Tris, $44.5 \mathrm{mM}$ boric acid, and $1 \mathrm{mM}$ ethylenediaminetetraacetic acid, Sambrook et al., 1989). 
Table 1. Simple sequence repeat (SSR) primers used to analyze genetic diversity in 15 sul lines of sweet corn.

\begin{tabular}{|c|c|c|c|}
\hline Primers & Motif & Sequence $\left(5^{\prime} \rightarrow 3^{\prime}\right)$ & Chromosome \\
\hline UMC2071 & $(\mathrm{ATGT})_{5}$ & $\begin{array}{l}\text { F: ACTGATGGTGTTCTTGGGTGTTTT } \\
\text { R: ATACACGCAGTTACCCGAAGGTT }\end{array}$ & 3 \\
\hline UMC1636 & $(\mathrm{ACTGC})_{4}$ & $\begin{array}{l}\text { F: GTACTGGTACAGGTCGTCGCTCTT } \\
\text { R: ATATCAGTCGTTCGTCCAGCTAA }\end{array}$ & 9 \\
\hline Uмc1241 & $(\text { GTCTTTG })_{4}$ & $\begin{array}{l}\text { F: TGAAGCAAGTCACTGGTAAGAGCA } \\
\text { R: TGACACACCCATACTTCCAACAAG }\end{array}$ & 7 \\
\hline Uмс2293 & $(\text { TCTCTCTC })_{4}$ & $\begin{array}{l}\text { F: ATGTTCCGTTTATTATTTGCCCG } \\
\text { R: AAAGAACAGACGGGATCCAATC }\end{array}$ & 5 \\
\hline Uмс2350 & $(\mathrm{GGCCGT})_{4}$ & $\begin{array}{l}\text { F: CGAATCGAGGATGGTTTGTTTTT } \\
\text { R: AGTAGCGACTCCTCTGCGTGAG }\end{array}$ & 10 \\
\hline Uмс2383 & $(\mathrm{AGC})_{6}$ & $\begin{array}{l}\text { F: CTCGCAACTGCGCTTCTAGATACT } \\
\text { R: CATAGACGTGCCCCTTGTCATC }\end{array}$ & 1 \\
\hline Uмс1363 & $(\mathrm{ACG})_{4}$ & $\begin{array}{l}\text { F: TGTTTAAGTGTTGGCAGAAAGCAA } \\
\text { R: TCTCCCTCCCCTGTACATGAATTA }\end{array}$ & 1 \\
\hline Uмс1590 & $(\mathrm{AAGGAG})_{5}$ & $\begin{array}{l}\text { F: CAGAGTCTGATAGTCCGAACCCAG } \\
\text { R: GTAAAGCTCACAGCTTCCGACAG }\end{array}$ & 1 \\
\hline Uмc1383 & $(\mathrm{GACG})_{6}$ & $\begin{array}{l}\text { F: CACACACATCGATCATGAGCATAC } \\
\text { R: GTGTACTACCATCAGACCCATCCA }\end{array}$ & 1 \\
\hline BNLG1083 & $\mathrm{AG}_{29}$ & $\begin{array}{l}\text { F: ACAGTCTGTTGGGGAACAGG } \\
\text { R: CAACGCTGGTTTGTCGTTTA }\end{array}$ & 1 \\
\hline UMC1506 & $(\mathrm{AACA})_{4}$ & $\begin{array}{l}\text { F: AAAAGAAACATGTTCAGTCGAGCG } \\
\text { R: ATAAAGGTTGGAAAACGTAGCCT }\end{array}$ & 10 \\
\hline Uмс1077 & $(\mathrm{CA})_{15}(\mathrm{CGCA})_{12}$ & $\begin{array}{l}\text { F: CAGCCACAGTGAGGCACATC } \\
\text { R: CAGAGACTCTCCATTATCCCTCCA }\end{array}$ & 10 \\
\hline UMC1292 & $(\mathrm{TGG})_{6}$ & $\begin{array}{l}\text { F: GAAGTGGGGAACATGGTTAATGTC } \\
\text { R: TCACGGTTCAGACAGATACAGCTC }\end{array}$ & 1 \\
\hline UMc1736 & $(\mathrm{GCAT})_{6}$ & $\begin{array}{l}\text { F: CCATCCACCACTAGAAAGAGAGGA } \\
\text { R: TTAATCGATCGAGAGGGTGCTTTTC }\end{array}$ & 2 \\
\hline BNLG1063 & $\mathrm{AG}_{42}$ & $\begin{array}{l}\text { F: GGAGACAACCCCGACGAC } \\
\text { R: GGTACCAGAGCCACAGATCC }\end{array}$ & 3 \\
\hline
\end{tabular}

The size of the amplified fragments was estimated using a 100-bp molecular weight marker (Invitrogen). The gels were subjected to an electric field of 60 volts for approximately $5 \mathrm{~h}$ and stained with $0.5 \mu \mathrm{L} / \mathrm{mg}$ ethidium bromide. The band patterns were visualized and photographed with a High Performance Ultraviolet Transilluminator, Edas 290 - USA, using the program Kodak 1D 3. The number of alleles per locus was determined based on the relative position of bands on the gel.

The genetic variability in 15 sweet corn progenies was analyzed by calculating the mean observed and expected heterozygosity, number of alleles, effective number of alleles per polymorphic locus, percentage of polymorphic loci, fixation index $\left(F_{\text {IS }}\right)$, genetic similarity or distance coefficient, and values of Wright's F statistic (1965) $\left(F_{\mathrm{IT}}\right.$ and $\left.F_{\mathrm{ST}}\right)$ for the $15 \mathrm{sul}$ sweet corn lines. These parameters were estimated using the POPGENE software 1.32 (Yeh et al., 1999).

The genetic distance between the lines tested was estimated using the modified distance of Rogers (1972), and the distances between the lines in the S5 generation were calculated by the unweighted pair-group method based on arithmetic averages (UPGMA) using Genes, version 4.1 (Cruz, 2006).

\section{RESULTS}

Of the 100 microsatellite primer pairs isolated for field corn and tested for sweet corn, 85 amplified products were detected. Primers were selected using 2 randomly chosen 
DNA samples, and were analyzed on MS-8 agarose gels to verify the complementarity and reproducibility of the primers. Seventy primers were monomorphic for all samples tested, and only 15 primers amplified 2 or more products. It is possible that the lack of amplification was because the primers were designed for SSR loci of field corn that were not complementary to DNA segments of the sweet corn genome. The estimated proportion of polymorphic loci in the 15 lines was $17.65 \%$.

The number of alleles detected per loci with the 15 polymorphic primers ranged from 2 to 4 . These 15 primers were distributed on 7 chromosomes, and 39 alleles were detected, with an average of 2.60 alleles per locus. The highest number of alleles was observed at the loci Umc1241 and Bnlg1083 (Table 2).

Table 2. Number of alleles $\left(N_{\mathrm{A}}\right)$ and the effective number of alleles per polymorphic SSR locus $\left(N_{\mathrm{E}}\right)$, mean observed $\left(H_{\mathrm{O}}\right)$ and mean expected heterozygosity $\left(H_{\mathrm{E}}\right)$, and the coefficients of fixation $\left(F_{\mathrm{IS}}, F_{\mathrm{IT}}, F_{\mathrm{ST}}\right.$; Wright, $1965)$ in $15 \mathrm{sul}$ sweet corn progenies.

\begin{tabular}{|c|c|c|c|c|c|c|c|}
\hline Locus & $N_{\mathrm{A}}$ & $N_{\mathrm{E}}$ & $H_{\mathrm{O}}$ & $H_{\mathrm{E}}$ & $F_{\text {IS }}$ & $F_{\text {IT }}$ & $F_{\mathrm{ST}}$ \\
\hline Umc1736 & 2.0000 & 1.6344 & 0.5270 & 0.3908 & -0.7808 & -0.3514 & 0.2412 \\
\hline Umc1636 & 2.0000 & 1.9942 & 0.1081 & 0.5019 & 0.4063 & 0.7851 & 0.6379 \\
\hline Umc2350 & 3.0000 & 2.7790 & 0.0541 & 0.6445 & 0.6571 & 0.9112 & 0.7410 \\
\hline Umc2383 & 2.0000 & 1.9769 & 0.0000 & 0.4975 & 1.0000 & 1.0000 & 0.9351 \\
\hline Umc2071 & 2.0000 & 1.4776 & 0.1892 & 0.3254 & -0.1475 & 0.4167 & 0.4917 \\
\hline Bnlg1063 & 2.0000 & 1.6000 & 0.0946 & 0.3776 & 0.0667 & 0.7489 & 0.7309 \\
\hline Umcl383 & 3.0000 & 2.4268 & 0.1486 & 0.5919 & 0.2466 & 0.7527 & 0.6717 \\
\hline Umc1363 & 2.0000 & 1.7070 & 0.1000 & 0.4172 & 0.1566 & 0.8094 & 0.7740 \\
\hline Umc1241 & 4.0000 & 2.7251 & 0.1622 & 0.6373 & 0.2834 & 0.7430 & 0.6414 \\
\hline Umc1292 & 3.0000 & 2.7117 & 0.0135 & 0.5432 & 0.8630 & 0.9752 & 0.8192 \\
\hline Umc1506 & 3.0000 & 2.3517 & 0.2568 & 0.5787 & -0.3659 & 0.5599 & 0.6778 \\
\hline Umc1077 & 2.0000 & 1.2067 & 0.0270 & 0.1725 & 0.1667 & 0.8424 & 0.8109 \\
\hline Umc2293 & 2.0000 & 1.9309 & 0.0000 & 0.4854 & 1.0000 & 1.0000 & 0.8680 \\
\hline Umc1590 & 3.0000 & 2.2103 & 0.4459 & 0.5513 & -0.5668 & 0.1742 & 0.4730 \\
\hline Bnlg1083 & 4.0000 & 3.0851 & 0.1622 & 0.6805 & 0.2768 & 0.7616 & 0.6704 \\
\hline Mean & 2.6000 & 2.0852 & 0.1526 & 0.4930 & 0.0329 & 0.6917 & 0.6812 \\
\hline
\end{tabular}

Null phenotypes were observed in 4 plants of line DN44 using primer UMC1363. The existence of a null allele in this line was confirmed by repeated amplifications.

The plants of some lines had an additional allele. The lines DN17.1 and DN6 showed a plant with an additional allele at locus Umc1590, while the lines DN7 and DN9 included 2 and 3 plants, respectively, with an extra allele at locus Umc1590. An additional band was observed with an intensity that was comparable to that of the 2 original alleles.

The triallelic pattern of SSR loci can be considered evidence of chimeras, a mechanism of genetic diversification that was described by Hocquigny et al. (2004) and was reported in grapevine clones (Moncada et al., 2006), in sweet corn progenies at the loci Umc1446, Umc1590, and Umc2343 (Rupp et al., 2009), and in popcorn genotypes at locus Umc1653 (Eloi, 2010). The presence of additional alleles seems important to indicate, for example, the potential stability or genetic diversification of genotypes. Although chimerism can be considered a minor influence in corn variability because this species reproduces by crossing, a third allele at an SSR locus indicates the potential of this locus for molecular diversity and variability (Rupp et al., 2009). However, because a chimeric situation was not clearly investigated, the third allele at the Umc 1590 locus was not considered in this paper.

The effective number of alleles was not equal for the 15 microsatellite loci. The highest effective number of alleles (3.08) and the highest mean expected heterozygosity $\left(H_{\mathrm{E}}=\right.$ 
$0.6805)$ were detected at locus Bnlg1083, and the lowest effective number of alleles (1.20) and the lowest mean expected heterozygosity $\left(H_{\mathrm{E}}=0.1725\right)$ were found at $U m c 1077$. The mean expected heterozygosity at all SSR loci was 0.4930 .

The high effective number of alleles per locus and high mean expected heterozygosity $\left(H_{\mathrm{E}}>0.50\right)$ detected at 7 SSR loci (Umc2350, Umc1383, Umc1241, Umc1292, Umc1506, Umc1590, and Bnlg1083) suggests that $47 \%$ of the 15 SSR loci would be sufficient to differentiate the 15 sweet corn progenies. Allele frequencies were analyzed for the 15 SSR loci.

The $F_{\text {IS }}$ values (Table 2) show a deficit of heterozygotes at the 15 studied loci $\left(F_{\text {IS }}=0.0329\right)$. The fixation index $\left(F_{\text {IS }}\right)$ was 1.0 at $U m c 2383$ and $U m c 2293$ in all 15 sul sweet corn progenies and was positive for $73.33 \%$ of the SSR loci. However, the overall deficit of heterozygous plants was low (3.29\%) for all SSR loci of the 15 progenies in the S5 generation. The $F_{\text {IS }}$ value was negative at the loci Umc1736, Umc2071, Umc1506, and Umc1590, indicating an excess of heterozygous plants at $26.66 \%$ of the loci. A high deficit of heterozygous markers was observed at the loci $U m c 1636, U m c 2350$, and $\operatorname{Umc1} 292\left(F_{\text {IS }}=0.4063,0.6571\right.$, and 0.8630, respectively). These high values, indicating an excess of homozygous markers at some loci, indicate a trend of fixation of certain alleles at these loci.

The high and positive $F_{\text {IT }}$ coefficient $\left(F_{\text {IT }}=0.69\right.$, Table 2$)$ reflects the overall inbreeding value, which was determined by non-random crosses forming the 15 sweet corn progenies, and is probably the result of self-pollination events in the selection process.

According to Wright (1978), $F_{\mathrm{ST}}$ values of $0.15-0.25$ and $>0.25$ indicate high and very high interpopulation divergence, respectively. The $F_{\mathrm{ST}}$ value was $<0.55$ at only 1 locus (Umc1736), showing that the 15 analyzed sweet corn progenies are highly differentiated for the 15 analyzed SSR loci, forming genetically structured populations. The greatest genetic differentiation was observed at locus $U m c 2383\left(F_{\mathrm{ST}}=0.9351\right.$, Table 2$)$. The UMC2383 primer is therefore the primer that is most appropriate to differentiate the 15 progenies with regard to the differential frequency of alleles at this locus. The extremely high level of differentiation that was detected in the $15 \mathrm{sul}$ sweet corn progenies $\left(F_{\mathrm{ST}}=0.6812\right)$ indicates that the random events of genetic recombination in the generation and/or somatic recombination events in each genotype must be responsible for the estimated genetic variability. The $F_{\mathrm{ST}}$ value also indicated that $68.12 \%$ of the total variance in allele frequencies at the microsatellite loci was related to genetic differences among the $\mathrm{S} 5$ progenies.

The proportion of polymorphic loci was the highest in the progenies DN17.1, DN6, and DN9 (Table 3). In the group of 15 progenies, the mean proportion of polymorphic loci was $39.11 \%$. This mean proportion was lower than that reported in the studies by Liu et al. (2003) (54\%) and Eloi (2010) (76.66\%) for hybrid and open-pollinated popcorn populations. This evidence supports the statement of Matsuoka et al. (2002) that microsatellites are more variable in the original species from which they were derived than in closely related species. According to Liu et al. (2003), popcorn belongs to the same species as field corn. However, comparative studies of the genetic diversity at SSR loci of open-pollinated lines and populations of field corn of other species of the genus Zea and of corn with special characteristics such as sweet corn and popcorn showed that the number of alleles per locus and the mean heterozygosity values of popcorn were lower than those of field corn.

The mean observed heterozygosity varied from 0.0533 to 0.3067 , and the expected heterozygosity was between 0.0475 and 0.3422 . The proportion of expected heterozygous plants of progeny DN19 was the highest (0.3422), and the observed proportion of heterozygous plants was highest (0.3067) for the progenies DN19 and DN17.1 (Table 3). These 
progenies with the highest heterozygosity are considered promising for continuous selection. The maintenance of the genetic diversity during the development of progenies is important for the selection progress to increase the possibilities for selection in the medium and long term.

Table 3. Number of polymorphic SSR loci $\left(N_{\mathrm{p})}\right)$, number of observed alleles $\left(N_{\mathrm{A}}\right)$, effective number of alleles $\left(N_{\mathrm{E}}\right)$, proportion of polymorphic loci $(\% \mathrm{P})$, and mean observed $\left(H_{\mathrm{O}}\right)$ and expected heterozygosity $\left(H_{\mathrm{E}}\right)$ in 15 sul sweet corn progenies.

\begin{tabular}{|c|c|c|c|c|c|c|}
\hline Progeny & $N_{\mathrm{pl}}$ & $N_{\mathrm{A}}$ & $N_{\mathrm{E}}$ & $\% \mathrm{P}$ & $H_{\mathrm{O}}$ & $H_{\mathrm{E}}$ \\
\hline DN22 & 6 & 1.4667 & 1.3227 & 40.00 & 0.0800 & 0.1867 \\
\hline DN8 & 4 & 1.2667 & 1.1895 & 26.67 & 0.1067 & 0.1215 \\
\hline DN17.2 & 8 & 1.6000 & 1.4926 & 53.33 & 0.1867 & 0.2756 \\
\hline DN32.1 & 4 & 1.4000 & 1.3224 & 26.67 & 0.1000 & 0.1476 \\
\hline DN19 & 10 & 1.7333 & 1.5937 & 66.67 & 0.3067 & 0.3422 \\
\hline DN17.1 & 11 & 1.7333 & 1.4782 & 73.33 & 0.3067 & 0.2978 \\
\hline DN6 & 11 & 1.8000 & 1.4747 & 73.33 & 0.3200 & 0.3037 \\
\hline DN7 & 7 & 1.5333 & 1.3631 & 46.67 & 0.1733 & 0.1970 \\
\hline DN4 & 5 & 1.3333 & 1.7221 & 33.33 & 0.1333 & 0.1126 \\
\hline DN9 & 6 & 1.4000 & 1.2789 & 40.00 & 0.1067 & 0.1748 \\
\hline DN23 & 3 & 1.2000 & 1.1647 & 20.00 & 0.1333 & 0.0978 \\
\hline DN28 & 3 & 1.2000 & 1.1596 & 20.00 & 0.0933 & 0.0963 \\
\hline DN44 & 4 & 1.2857 & 1.1739 & 26.67 & 0.1071 & 0.1276 \\
\hline DN45 & 4 & 1.2667 & 1.1557 & 26.67 & 0.0533 & 0.1067 \\
\hline DN47 & 2 & 1.1333 & 1.0787 & 13.33 & 0.0778 & 0.0475 \\
\hline Mean & 5.86 & 1.4234 & 1.3313 & 39.11 & 0.1523 & 0.1756 \\
\hline
\end{tabular}

Rogers distance matrices (1972) were used to construct the dendrogram. Figure 1 shows the dendrogram that was generated from the dissimilarity matrix based on the clustering of the genotypes assessed from the estimated distances using the UPGMA distances. This grouping shows the genetic divergence that was found in the analysis of 15 microsatellites in 15 lines of sul sweet corn. At a cut-off level of $90 \%$, the UPGMA dendrogram showed the formation of 4 major groups: group 1 included 10 progenies (DN19, DN6, DN7, DN17.1, DN22, DN17.2, DN9, DN32.1, DN4, and DN47), group 2 consisted of progeny DN45, group 3 included 3 progenies (DN23, DN28, and DN44), and group 4 consisted of progeny DN8. Group 4 had the highest level of genetic differentiation when compared with the plants in groups 1, 2, and 3. The Rogers distance values ranged from 0.3204 (lines DN19 and DN6) to 0.7603 (lines DN9 and DN28).

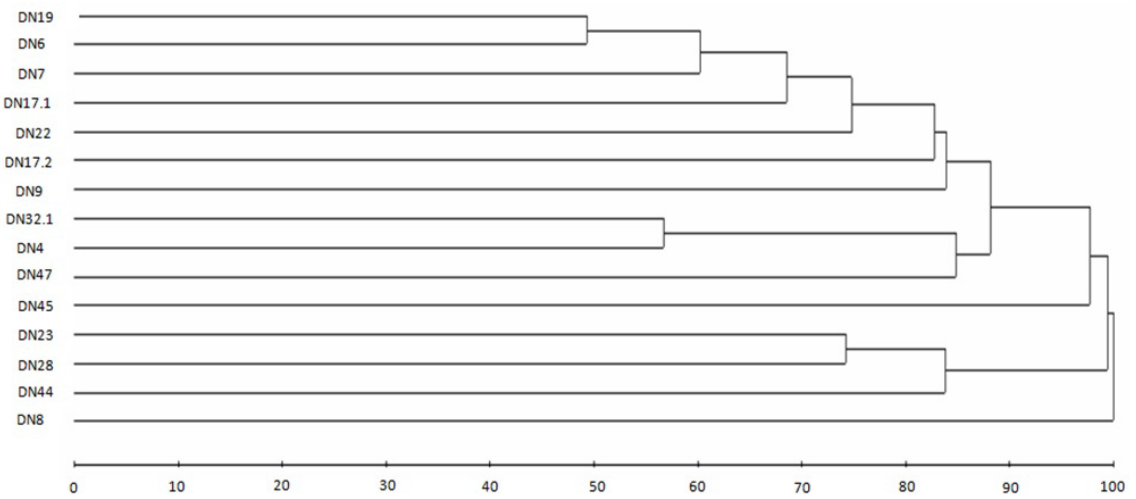

Figure 1. Grouping of the $15 \mathrm{sul}$ sweet corn lines by the unweighted pair-group method based on arithmetic averages. 
The same Rogers distance matrix (1972) was used to divide the genotypes into groups according to the Tocher optimization method (Rao, 1952). This method resulted in the formation of 8 groups (Table 4): groups 1 and 2 were each formed by 2 lines (DN8 and DN22, and DN19 and DN17.2, respectively), group 3 consisted of lines DN32.1 and DN17.1, group 4 was represented by lines DN4 and DN6, group 5 contained lines DN7 and DN9, group 6 included the 2 lines DN23 and DN28, group 7 included lines DN45 and DN47, and group 8 consisted of line DN44.

\section{Table 4. Grouping of the lines by the Tocher optimization method applied to the Rogers distance matrix.}

\begin{tabular}{lc}
\hline \multicolumn{2}{c}{ Group formation } \\
\hline Group & Lines \\
\hline 1 & 1,2 \\
2 & 3,5 \\
3 & 4,6 \\
4 & 7,9 \\
5 & 8,10 \\
6 & 11,13 \\
7 & 12,14 \\
8 & 15 \\
\hline
\end{tabular}

Based on the original results, the relative position of the genotypes can be projected in 3 dimensions (Figure 2). The relative position of the lines in this figure indicates that lines DN22, DN8, and DN45 are the farthest from the other lines, partially corroborating the UPGMA clustering results when one considers that lines DN8 and DN45 formed independent groups.

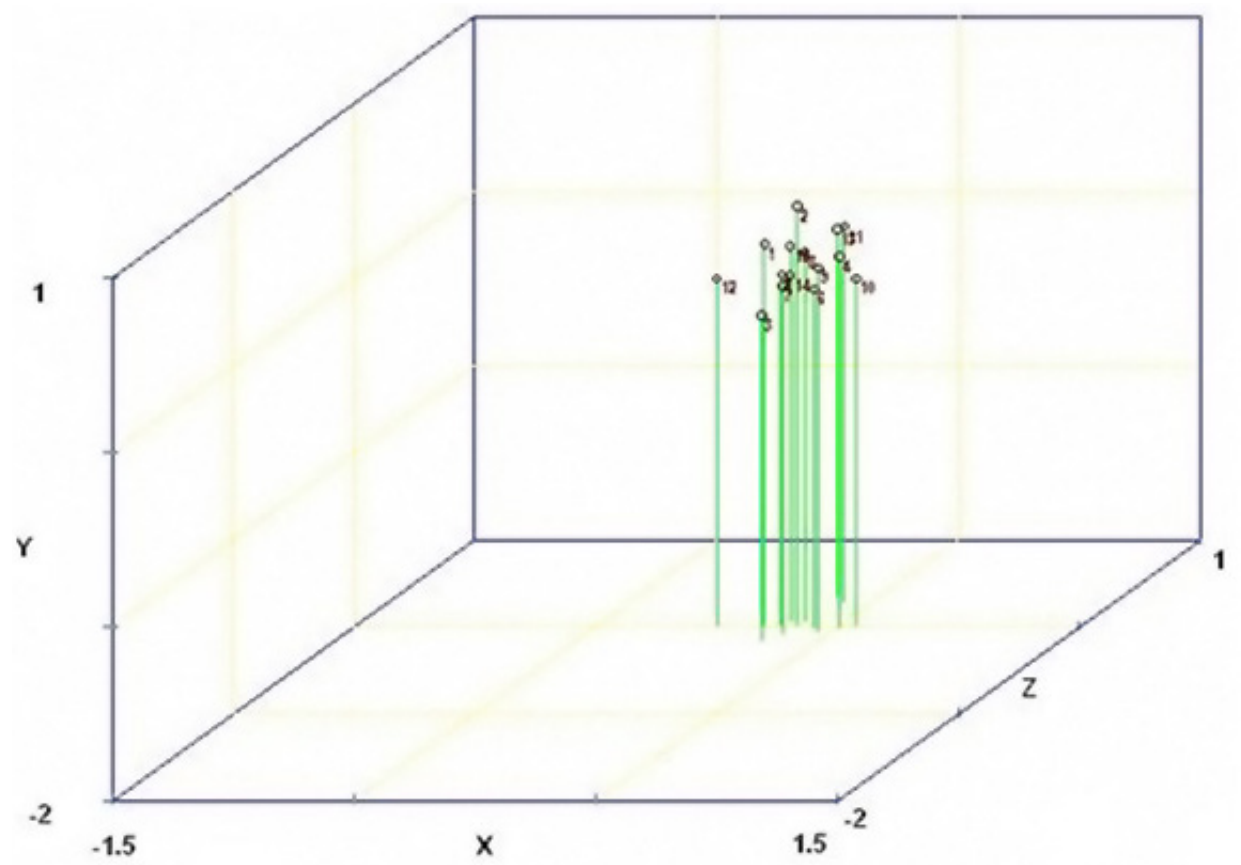

Figure 2. Projection of distances in space without transformation (root) and without data rotation for 15 sweet corn lines. 


\section{DISCUSSION}

The proportion of polymorphic loci in the $15 \mathrm{sul}$ sweet corn lines was $17.64 \%$. However, an important finding of this study was that $85 \%$ of the primers derived from field corn and selected from genomic libraries and databases can be efficiently applied to analyze the genetic structure and diversity of sweet corn. A few SSR loci have been used so far to characterize the genetic diversity of Brazilian sweet corn (Bered et al., 2005; Rupp et al., 2009). Our results may stimulate the use of SSR primers derived from field corn (mainly primers of the UMC maize group) to analyze the genetic structure and diversity among sweet corn populations.

Null alleles were detected in the sweet corn line DN44 with primer UMC1363. Null allele frequencies are relatively high in a number of corn cultivars (Matsuoka et al., 2002). Mutations in the flanking regions of microsatellite repeats were used by Rupp et al. (2009) to explain the low efficacy of some primers to amplify the SSR loci and to explain the frequency of the null alleles. According to Alvarez et al. (2001), null alleles can occur at microsatellite loci because not all regions of the primers determine the effective amplification in all samples because of possible mutations in the annealing regions that are complementary to the primers. The results of re-amplification (under the same PCR conditions) were not different, confirming the occurrence of null alleles, which may also be related to errors (e.g., using the wrong volumes in the amplification reactions of the same sample) in the PCR reaction. Rupp et al. (2009) stated that, in practical terms, 1 or 2 re-amplification reactions can be an important improvement to reduce the high frequency of null alleles detected in different corn cultivars.

The mean estimated number of alleles in $15 \mathrm{sul}$ sweet corn lines ( 2.60 alleles/locus) is lower than that reported for open-pollinated populations of sweet corn. A high mean number of alleles (4.2 and 6.0) was detected in 3 and 13 open-pollinated populations (Bered et al., 2005). The analysis of 6 SSR loci in the open-pollinated cultivar BR401 by Bered et al. (2005) showed a mean number of alleles of 4.2. Liu et al. (2005) detected a mean of 4.1 alleles with 50 SSR primers in 38 field corn varieties. The results of this study indicate that an allele loss and reduction in the number of alleles may have occurred during the 5 generations of selfing in the 15 sul sweet corn lines.

Although the presence of a third allele at locus Umc1590 was not addressed in this study, according to Rupp et al. (2009), new alleles can arise through mutations or mitotic recombination events at the SSR loci, which can raise the level of polymorphism in the SSR loci of sweet corn lines. In 101 lines representing tropical genotypes from the United States and Canada, $0.02 \%$ had 3 or more alleles per microsatellite (Matsuoka et al., 2002).

The estimated mean number of alleles in the $15 \mathrm{sul}$ sweet corn lines (2.60 alleles/ locus) and mean expected heterozygosity $\left(H_{\mathrm{E}}=0.1725-0.6805\right)$ were lower than the mean number of alleles (5.0-6.9) and the mean expected heterozygosity $\left(H_{\mathrm{E}}=0.59-0.62\right)$ detected in field corn lines (Senior et al., 1998) and in 5 sweet corn lines from the United States and Europe (2.89 alleles/locus and $H_{\mathrm{E}}=0.64$; Liu et al., 2003). The estimated genetic diversity from the mean expected heterozygosity was not analyzed in detail in other studies with different populations (Bered et al., 2005) and sweet corn lines (Srdić et al., 2008). In the 15 sul sweet corn lines of cultivar BR-401, the Rogers distance matrix values (1972) ranged from 0.3204 (progenies DN19 and DN4) to 0.7603 (progenies DN9 and DN28), showing a broad genetic base for the $15 \mathrm{sul}$ sweet corn lines in contrast to the narrow genetic base reported for sweet corn lines (Srdić et al., 2008). 
In this study, the clear differentiation between sul lines in the S5 generation $\left(F_{\mathrm{ST}}=0.6812\right)$ suggested the formation of heterotic groups. According to Wright (1978), values between 0.15 and 0.25 indicate a high level of interpopulation divergence. The genetic relationship between individual plants of different groups can help select parents to establish crosses to breed the base population and to maximize heterosis.

An excess of heterozygous plants was observed in lines DN19, DN17.1, and DN6, indicating the possibility of continuous selection in the medium and long term. High values for the proportion of polymorphic loci and observed and expected heterozygosity in most progenies (DN17.2, DN19, DN17.1, DN6, and DN7) showed that 5 selection cycles did not induce relevant changes in the plant material. The overall $F_{\text {IS }}$ value $(0.0329)$ indicated a $3.29 \%$ excess of homozygous plants after 5 selection cycles. The high heterozygosity detected in the SSR loci in DN19, DN17.1, and DN6 can be an important observation because a high heterozygosity indicates that the plant population has a substantial amount of adaptive genetic variations to escape the effect of a control agent limiting the plant development and maintenance (Allendorf and Luikart, 2007).

The loci with a deficit of heterozygotes can be a target of directed selection along with the loci for agronomic traits of interest in certain genotypes. According to this hypothesis, the loci Umc1636, Umc2350, and Umc1292 could be linked to quantitative trait loci.

While the selection was apparently strong at some SSR loci (Umc2383 and Umc2293), showing a deficit of heterozygous plants, a significant excess of heterozygous markers $(78.08 \%)$ was detected at locus Umc1736 and a moderate excess was detected at locus Umc1506 (36.59\%). The levels of genetic variation at the $15 \mathrm{SSR}$ loci of sul sweet corn lines are therefore relatively low and high. Vigouroux et al. (2005) provided evidence that the domestication and artificial selection of morphological and agronomic traits in corn had no significant effect on the level of genetic variation at SSR loci.

The organization of the dendrogram indicates that crosses between plants of progeny DN19 with plants of progeny DN8, for example, are promising to broaden the genetic base of sweet corn. In this study, the use of molecular markers also targeted inferences about the interpopulational heterotic potential; the genotypes with the greatest genetic distance from each other (and, conversely, with the lowest similarity values) can be exploited in reciprocal recurrent selection programs to synthesize contrasting lines, which can be intercrossed to generate superior hybrids. The consistency of the results involving genotypes DN8 and DN19 allow the assumption that interpopulation crosses between these would be a promising alternative to obtain heterozygosity as a strategy to address the exploitation of heterosis.

The clustering methods (Tocher and UPGMA) differ in relation to the number of groups formed ( 8 and 4 , respectively) and to the components of each group. According to Dudley (1994), the method of distance means (UPGMA) can be considered superior to other methods, and it has been recommended by some authors (Romesburg, 1984). Therefore, this method should be used to establish recommendations for future crosses. Verifying the distances between the genotypes by the dispersion of the points they represent in 3 dimensions was helpful in the analysis of the divergence between the lines. Furthermore, it indicated that the Tocher method probably discriminated the lines less clearly than the UPGMA method. According to Munhoz et al. (2009), the genetic variability among plant specimens is one of the pillars of genetic improvement, be it to identify genetically distant genotypes for crosses to breed superior hybrids and segregating genotypes, to assess the degree of genetic erosion, 
or to deepen the knowledge of the genetic basis of genotypes used to cultivate or undergodomestication and adaptation.

Li et al. (2002) summarized the available data reported for SSR distribution in coding and noncoding regions of genomes and the functional importance of SSRs. Despite the wide differences between organisms, recent analyses (Subirana and Messeguer, 2008) indicated that microsatellites with different repeat motifs may be structurally related and involved in determining the chromosome structure. Despite the small number of alleles found in the 15 lines, the UEM-sugary-1 germplasm collection can be considered an important genetic reservoir for the future generation of different sul lines and the production of cultivars. The analyses of the genetic structure of sul sweet corn progenies using SSR markers were important to estimate the genetic distance or similarity between the progenies. These analyses were especially important to identify SSR loci with low heterozygosity levels to identify progenies in the S5 generation with $100 \%$ homozygous plants and lines with high heterozygosity, which should be the goal of this continuous selection in the medium and long term.

\section{ACKNOWLEDGMENTS} nológico.

Research supported by the Conselho Nacional de Desenvolvimento Científico e Tec-

\section{REFERENCES}

Allendorf FW and Luikart G (2007). Conservation and the Genetics of Populations. Blackwell Publishing, Maden.

Alvarez AE, Van de Wiel CCM, Smulders MJM and Vosman B (2001). Use of microsatellites to evaluate genetic diversity and species relationships in the genus Lycopersicon. Theor. Appl. Genet. 103: 1283-1292.

Barbieri VHB, Luz JMQ, Brito CH and Duarte JM (2005). Produtividade e rendimento industrial de híbridos de milho doce em função de espaçamento e populações de plantas. Hortic. Bras. 23: 826-830.

Bered F, Terra TF, Spellmeier M and Barbosa Neto JF (2005). Genetic variation among and within sweet corn populations detected by RAPD and SSR markers. Crop Breed. Appl. Biotechnol. 5: 418-425.

Bordallo PN, Pereira MG, Amaral Júnior AT and Gabriel APC (2005). Análise dialélica de genótipos de milho doce e comum para caracteres agronômicos e proteína total. Hortic. Bras. 23: 123-127.

Cruz CD (2006). Programa Genes: Biometria. Editora UFV, Viçosa.

Don RH, Cox PT, Wainwright BJ, Baker K, et al. (1991). 'Touchdown' PCR to circumvent spurious priming during gene amplification. Nucleic Acids Res. 19: 4008.

Dudley JW (1994). Comparison of Genetic Distance Estimators Using Molecular Marker Data. In: Analysis of Molecular Marker Data American Society for Horticultural Science and Crop Science Society of America, Corvallis, 3-7.

Eloi IBO (2010). Marcadores Microssatélites Para a Análise da Variabilidade Genética e da Estrutura de Populações de Milho Pipoca (Zea mays L.). Master's thesis, UEM, Maringá.

Garcia JLM, Bernhardt LW, Bleinroth EW and Mori EEM (1978). Determinação do ponto de colheita do milho-doce. Bol. Inst. Tecnol. Alim. 58: 107-127.

Hocquigny S, Pelsy F, Dumas V, Kindt S, et al. (2004). Diversification within grapevine cultivars goes through chimeric states. Genome 47: 579-589.

Hoisington D, Khairallah M and González-Léon D (1994). Laboratory Protocols: CIMMYT Applied Molecular Genetics Laboratory. CIMMYT, México.

Laborda PR (2003). Diversidade Genética entre Linhagens de Milho Tropical: Estudo com Base em Marcadores Moleculares. Master's thesis, UNICAMP, Campinas.

Li YC, Korol AB, Fahima T, Beiles A, et al. (2002). Microsatellites: genomic distribution, putative functions and mutational mechanisms: a review. Mol. Ecol. 11: 2453-2465.

Liu K, Goodman M, Muse S, Smith JS, et al. (2003). Genetic structure and diversity among maize inbred lines as inferred from DNA microsatellites. Genetics 165: 2117-2128.

Liu YJ, Huang YB, Rong TZ and Tian ML (2005). Comparative analysis of genetic diversity in land-races of waxy maize 
from Yunnan and Guizhou using SSR markers. Sci. Agric. Sini. 4: 648-653.

Matsuoka Y, Vigouroux Y, Goodman MM, Sanchez GJ, et al. (2002). A single domestication for maize shown by multilocus microsatellite genotyping. Proc. Natl. Acad. Sci. U. S. A. 99: 6080-6084.

Moncada X, Pelsy F, Merdinoglu D and Hinrichsen P (2006). Genetic diversity and geographical dispersal in grapevine clones revealed by microsatellite markers. Genome 49: 1459-1472.

Munhoz RE, Prioli AJ, Amaral AT Jr, Scapim CA, et al. (2009). Genetic distances between popcorn populations based on molecular markers and correlations with heterosis estimates made by diallel analysis of hybrids. Genet. Mol. Res. 8: 951-962.

Nascimento WM, Pessoa HBSV and Boiteux LS (1994). Qualidade fisiológica de sementes de milho doce submetidas a diferentes processos de colheita, debulha e beneficiamento. Pesqui. Agropec. Bras. 29: 1211-1214.

Nigussie M and Saleh G (2007). Genetic variability and responses to two methods of recurrent selection in two sweet corn (Zea mays L. Saccharata) populations. Asian J. Plant Sci. 6: 859-863.

Oliveira Júnior LFG, Pereira MG and Bressan-Smith R (2006). Caracterização e avaliação agronômica de híbridos e linhagens de milho doce (su1). Hortic. Bras. 24: 283-288.

Padilha L, Guimarães CT and Paiva E (2003). Avaliação da pureza genética em sementes de milho utilizando marcadores microssatélites. Circular Técnica 30: 65-67.

Rao CR (1952). Advanced Statistical Methods in Biometric Research. John Wiley and Sons, New York.

Reifschneider FJB, Gama EEG and Reis NVB (1984). Milhos Doces Superdoce (BR400), Doce de Ouro (BR401) e Doce Cristal (402). Hortic. Bras. 2: 53-54.

Rogers JS (1972). Measures of Genetic Similarity and Genetic Distance. In: Studies in Genetics University of Texas, Austin, 145-153.

Romesburg HC (1984). Cluster Analysis for Researchers. Lulu Press, Raleigh.

Rupp JV, Mangolin CA, Scapim CA and Machado MFPS (2009). Genetic structure and diversity among sweet corn (su1germplasm) progenies using SSR markers. Maydica 54: 125-132.

Sambrook J, Fritsch EF and Maniatis T (1989). Molecular Cloning: A Laboratory Manual. 2nd edn. Cold Spring Harbor Laboratory Press, Cold Spring Harbor.

Senior ML, Murphy JP, Goodman MM and Stuber CW (1998). Utility of SSRs for determining genetic similarities and relationship in maize using an agarose gel system. Crop Sci. 38: 1088-1098.

Silva WJ, Teixeira JPF, Arruda P and Lovato MB (1978). Nutrimaiz, a tropical sweet maize cultivar of high nutritional value. Maydica 23: 129-136.

Srdić J, Nikolić A and Pajić Z (2008). SSR markers in characterization of sweet corn inbred lines. Genetika 40: 169-177.

Storck L and Lovato C (1991). Milho doce. Cienc. Rural 21: 283-292.

Subirana JA and Messeguer X (2008). Structural families of genomic microsatellites. Gene 408: 124-132.

Tracy WF, Whitt SR and Buckler ES (2006). Recurrent mutation and genome evolution: example of Sugary1 and the origin of sweet maize. Crop Sci. 46: 1-7.

Vigouroux Y, Mitchell S, Matsuoka Y, Hamblin M, et al. (2005). An analysis of genetic diversity across the maize genome using microsatellites. Genetics 169: 1617-1630.

Wann EV, Brown GB and Hills WA (1971). Genetic modifications of sweet corn quality. J. Am. Soc. Hortic. Sci. 96: 441-444.

Wright S (1965). The interpretation of population structure by F-statistics with special regards to systems of mating. Evolution 19: 395-420.

Wright S (1978). Evolution and the Genetics of Populations. University of Chicago Press, Chicago.

Yeh FC, Boyle TYZ and Xiyan JM (1999). POPGENE Version 1.31: Microsoft Window-Based Freeware for Population Genetic Analysis. University of Alberta and Center for International Forestry Research. 